\title{
Predictive maintenance for rotating machinery by using vibration analysis
}

\author{
N. Jamil1 ${ }^{1}$ M.F. Hassan², S.K. Lim¹ ${ }^{1}$ and A.R. Yusoff ${ }^{1}$ \\ 1 Department of Industrial Engineering, College of Engineering, Universiti Malaysia Pahang, 26300 Gambang Kuantan, Pahang, Malaysia \\ Phone: +6095492688 \\ 2 Department of Mechanical Engineering, College of Engineering, Universiti Malaysia Pahang, 26300 Gambang Kuantan, Pahang, Malaysia
}

\begin{abstract}
This paper presents a complete and well tested virtual instrument $(\mathrm{VI})$ for computer numerical control (CNC) machine predictive maintenance. The national instrument (NI) hardware, LabVIEW software and accelerometer sensor are acquired for the vibration analysis integrated with virtual instrument were developed based on the vibration severity chart threshold in ISO 10816. Validation experiments of the predictive maintenance module were utilized on drilling and milling processes to test and verify the effectiveness of the module. Results obtained from current module can monitor and provide the machine conditions at different condition of good, satisfactory, unsatisfactory, and unacceptable for rotating machinery status according to the vibration severity chart as per ISO 10816.
\end{abstract}

ARTICLE HISTORY

Received: $14^{\text {th }}$ Feb 2021

Revised: $11^{\text {th }}$ July 2021

Accepted: $15^{\text {th }}$ Aug 2021

\section{KEYWORDS}

Virtual instrument; condition monitoring; rotating machinery; predictive maintenance; vibration severity chart.

\section{INTRODUCTION}

Predictive maintenance, also known as machining monitoring, is a well-known but unresolved manufacturing engineering problem [1]. Numerous number of researchers have tried to develop an extremely general and accurate predictive monitoring system, but many aspects need to be improved, especially the detection and estimation approaches for intermittent machining [2]. Over the last two decades, it has been fine-tuned. According to [3], the conditions involved in machining are well understood, but regulating the process variable to achieve adequate responses is a difficult job. A virtual module of machining considers as a creative, user friendly yet informative three-dimensional computer simulation model. Main objective of using this virtual module for initial machining process planning stage is to improve quality of end product, reduce time and money waste, increase system operation to the fullest, decrease production modification orders, and avoid costly machine-tool breakage [4]. A virtual module of machining helps in the machining phase preparation. Until end product is produced, the virtual module makes sure that the planning of machining process and software used are accurate thoroughly. As a result, the environmental impact will be minimised. The concept of virtual module for machining process has been widely recognised and the simulations have previously been employed. Functions for assessing the environmental effects such as energy consumption, pollution, material mass loss, cutting fluid waste, lubricant oil waste and cutting tool use, can be included in a virtual machining model [5]. The virtual module of machining data, when combined with reference, method, and material properties sheet, were crucial and useful to decide the desired parameters. The simulation framework, using the virtual module, can analyse different machining approaches for environmental effect based on the modelling and analysis of this data.

LabVIEW (Laboratory Virtual Instrument Engineering Workbench) is a virtual programming software by National Instruments that creates applications using icons rather than lines of text. The user-friendly programming configuration can be discovered in numerous scientific fields and technical engineering as platform of monitoring [6], modelling [7] and simulation tools [8]. Many other monitoring applications of LabVIEW have been published in the literature [9-11]. As an advanced maintenance technique, this work established a simple, user friendly, but effective monitoring system that involves monitoring machine condition and predicting machine failure. It is important to boost performance, lower costs, and increase reliability as part of preventive maintenance.

Various variables in machining process can be measured and quite a few responses is predictable, such as AE [12], cutting force [13], power, and vibration [14]. The main focus of predictive maintenance is to look for potential damage before the damage occurs. In vibration measurement, vibration signal extracted from the sensor are used to predict and spot the deterioration of one machining condition or component [15]. Since the vibration is a combination of multiple vibrations at one time, thus a specific method is required to separate the observed component signal with another signal using FFT (Fast Fourier Transform) method [16, 17]. Furthermore, this signal is also processed in terms of velocity and displacement to obtain information on the state of the machine or equipment which is being monitored thoroughly [18].

The present work develops a predictive maintenance monitoring system using vibration-based data acquisition system. The vibration signal produced is then analysed via LabVIEW NI-based software evaluate and monitor machine condition. Experiment is carried out using the accelerometer to gather signal data for the threshold analysis as in vibration severity per ISO 10816 chart. The objectives of this work are to develop an effective and user friendly vibration-based VI module to monitor the present status of the machine for consistent and reliable predictive maintenance monitoring using 
LabVIEW, to acquire, visualize and analyse the vibration signal data on interpretation of machine condition and to correlate the vibration feature extraction (acceleration, velocity and displacement) with machine condition.

\section{INSTRUMENTATION AND EQUIPMENT}

\section{Principle of VI Acquisition and Data Analysis}

Predictive Maintenance can be defined as process of monitoring the condition and performance of equipment as it is operating to be able to predict when maintenance should be done. The basic principle of predictive maintenance is to take continuous measurements that allow for the prediction of which and when parts will break down. Vibration sensors are mounted on equipment during this analysis process, and data is collected, processed and warnings are generated based on the vibration outline. As soon as the warning is generated based on a specific vibration outline, non-working hours maintenance is scheduled, and the machine is repaired before it fails.

The scope of the VI developed involved three main parts. First, the module of predictive maintenance developed is only covering threshold or alarm limit for vibration severity as per ISO10816 (Figure 1). There are five major parts for ISO 10816 RMS alarm limits [19], which are as:

1) Part 1: General guidelines

2) Part 2: Large land-based steam turbine generator sets with capacity of more than $50 \mathrm{MW}$ are available

3) Part 3: When measured in place, industrial machines with a nominal power of more than $75 \mathrm{~kW}$ and nominal speeds of 120 to $15,000 \mathrm{rpm}$

4) Part 4: Sets operated by gas turbines, except aircraft derivatives

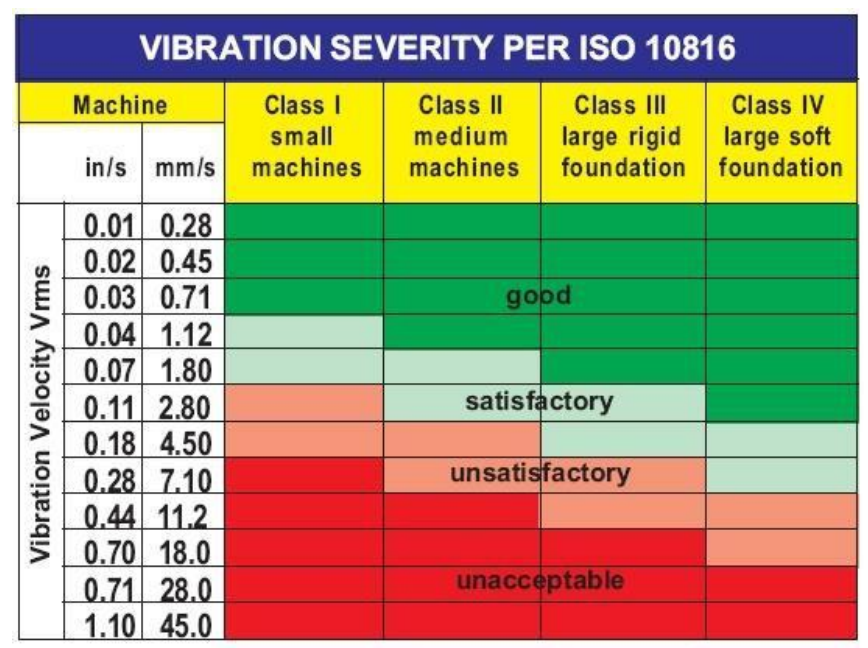

Figure 1. Interim broadband vibration criteria for specific machine group

Since the end user for this predictive maintenance is local's small and mid-size enterprises (SME) or any equivalent classification, it basically covers the Part 1: General guidelines which can be elaborated as in Table 1.

Table 1. Machine classification

\begin{tabular}{cl}
\hline Type of class & \multicolumn{1}{c}{ Definition } \\
\hline Class I & $\begin{array}{l}\text { Individual components of engines and machinery that are integrally related to the entire } \\
\text { system in normal operation. } \\
\text { (A typical example of a machine in this category is a production electrical motor with a } \\
\text { power rating of up to } 15 \mathrm{~kW}) .\end{array}$ \\
\hline Class II & $\begin{array}{l}\text { Medium sized machines (An electrical motors by output varying from 15W to } 75 \mathrm{~kW} \text { ) that } \\
\text { do not require special foundations, rigid mounted engines or machines (up to 300kW) that } \\
\text { do require special foundation. }\end{array}$ \\
\hline Class III & $\begin{array}{l}\text { Big prime movers and any larger devices with rotating masses built on rigid and heavy } \\
\text { foundations that are relatively stiff in the vibration measurement direction. }\end{array}$ \\
\hline Class IV & $\begin{array}{l}\text { Big prime movers and any large devices machines with rotating masses installed and } \\
\text { foundations that are comparatively soft in the vibration measurement direction. } \\
\text { (Gas turbines and turbo generators with outputs greater than 10MW, for example) }\end{array}$ \\
\hline
\end{tabular}


Next, the VI covers three out of four major monitoring process, which involves measurement, analysis process and alarm trigger. In general, there are two methods for triggering warning limit, i.e., threshold based analogue and control signal based automated digital triggering technique [13]. The principle of working on this VI acquisition is as follows: the data acquisition (DAQ) analogue's trigger circuit continuously converts the analogue into digital and tracks the analogue signal to see whether it meets the trigger criteria using LabVIEW VI. The acquisition produces an internal warning signal when the trigger conditions are reached, allowing the warning limit to be executed. Those internal signals will be processed in state of acceleration amplitude of vibrations before integrated into velocity and displacement. Moreover, as referring to the vibration severity chart, measurement of vibration velocity in term of rms with unit of in/s and $\mathrm{mm} / \mathrm{s}$ were taken as alarm limit for triggering process. A virtual instrument (VI) interface was designed after take every analysis detail into consideration. The design system consists of four main steps; cutting process monitoring, data acquisition, data processing, and machine condition recognition (Figure 2). Multiple experimental study was carried out subsequently under drilling and milling process to validate the VI system. Meanwhile, the last scope for VI development is the vibration measurement is only valid if the frequency range is up to $20,000 \mathrm{~Hz}$, which is the standard vibration measurement using accelerometer.

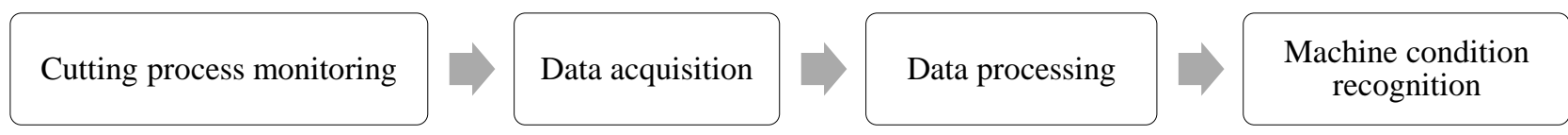

Figure 2. Milling process experiment for direct monitoring system

\section{System of Acquisition and Processing of Vibration Signal}

A virtual instrument was developed to measure vibration and the spectrum via LabVIEW. The VI consists of multiple tab layout and can be classified into three main components, as illustrate in Figure 3 and 4. There is general setting for user's control and measurement preferences, the graphical and numerical vibration measurement and the machining condition status to display. For general setting, selection of machine class type is vital to ensure the measurement and execution of alarm limit at correct threshold level.

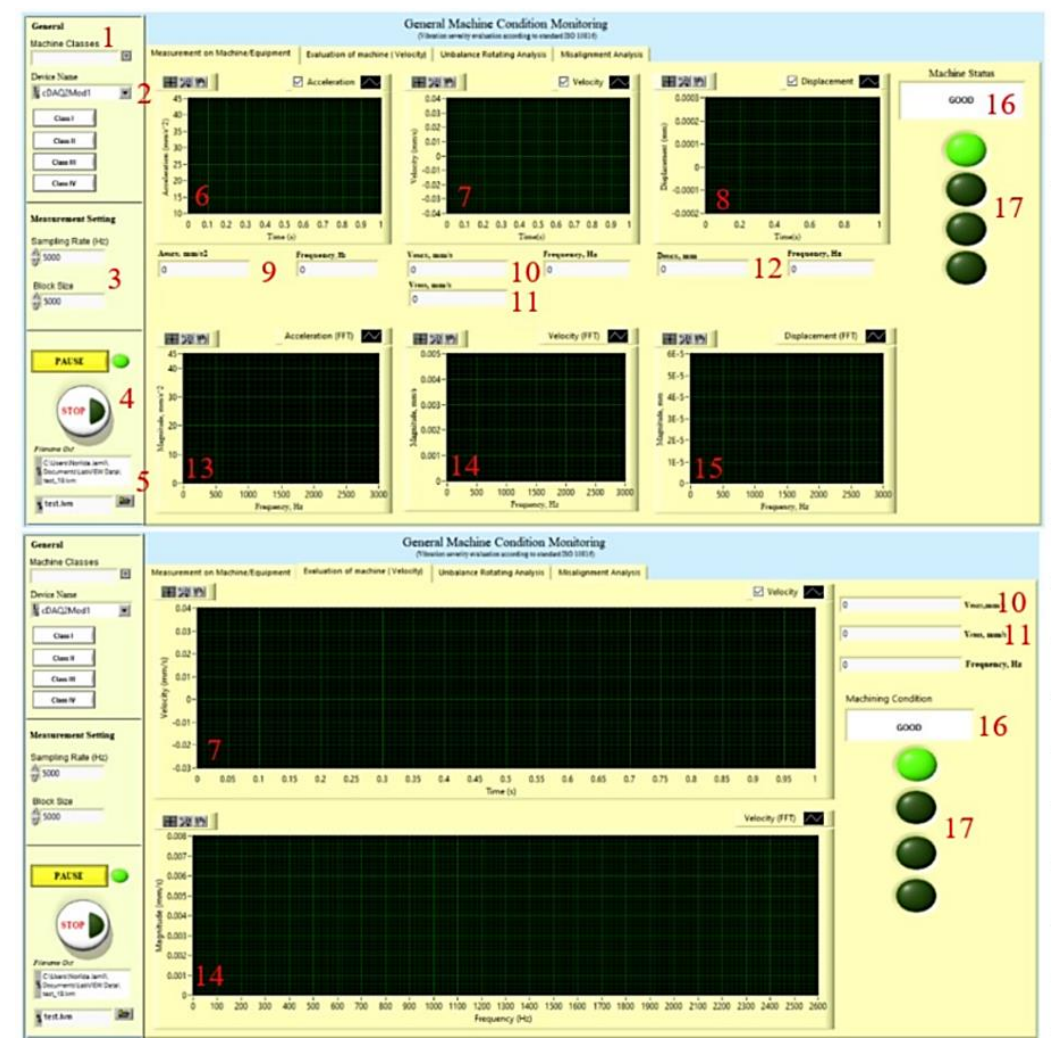

\begin{tabular}{c|l}
\hline No & \multicolumn{1}{|c}{ Details } \\
\hline 1 & Machine classification \\
\hline 2 & Data acquisition device \\
\hline 3 & Block size and sampling rate \\
\hline 4 & Start, pause and stop button \\
\hline 5 & Measurement file location \\
\hline 6 & Acceleration (time domain) \\
\hline 7 & Velocity (time domain) \\
\hline 9 & Displacement (time domain) \\
\hline 10 & Acceleration and frequency (peak) \\
\hline 11 & Velocity and frequency (peak) \\
\hline 12 & Displacement and frequency (peak) \\
\hline 13 & Acceleration (frequency domain) \\
\hline 14 & Velocity (frequency domain) \\
\hline 15 & Displacement (frequency domain) \\
\hline 16 & Monitoring condition status \\
\hline 17 & Monitoring condition level \\
\hline
\end{tabular}

Figure 3. Layout of virtual instrument for monitoring and processing vibration on machining

As for measurement, vibration amplitude (acceleration, velocity, and displacement) and FFT will be displayed along with reading taken from the amplitude peak, rms and frequency value. Meanwhile, on the right side of VI layout, machining condition status with four different severity level is observed. For second tab of VI, the vibrations data were measured using acceleration signal before integrated into velocity signal. Velocity signal type was chosen for 
standardizing measurement along with ISO 10816 threshold. The signals were also then visualized into peak, rms, and frequency value.

Table 2. Mathematical expression of vibration measurement

\begin{tabular}{|c|c|c|c|}
\hline Features of vibration & Definition & \multicolumn{2}{|c|}{ Function equation } \\
\hline Acceleration, $a$ & $\begin{array}{l}\text { Alteration of the velocity from vibration } \\
\text { object. }\end{array}$ & $a(t)=\frac{d v(t)}{d t}$ & (Eq. 1) \\
\hline Velocity, $v$ & Indicates how fast the object vibrates. & $v(t)=\int a(t) d t+C_{1}$ & (Eq. 2) \\
\hline Displacement, $x$ & Indicates how large the object vibrates. & $x(t)=\int v(t) d t+C_{2}$ & (Eq. 3) \\
\hline Root mean Square, RMS & $\begin{array}{l}\text { Root mean square of vibration amplitude } \\
\text { values. }\end{array}$ & $R M S=\sqrt{\frac{1}{n} \sum_{i=1}^{n} a_{i}^{2}}$ & (Eq. 4) \\
\hline
\end{tabular}

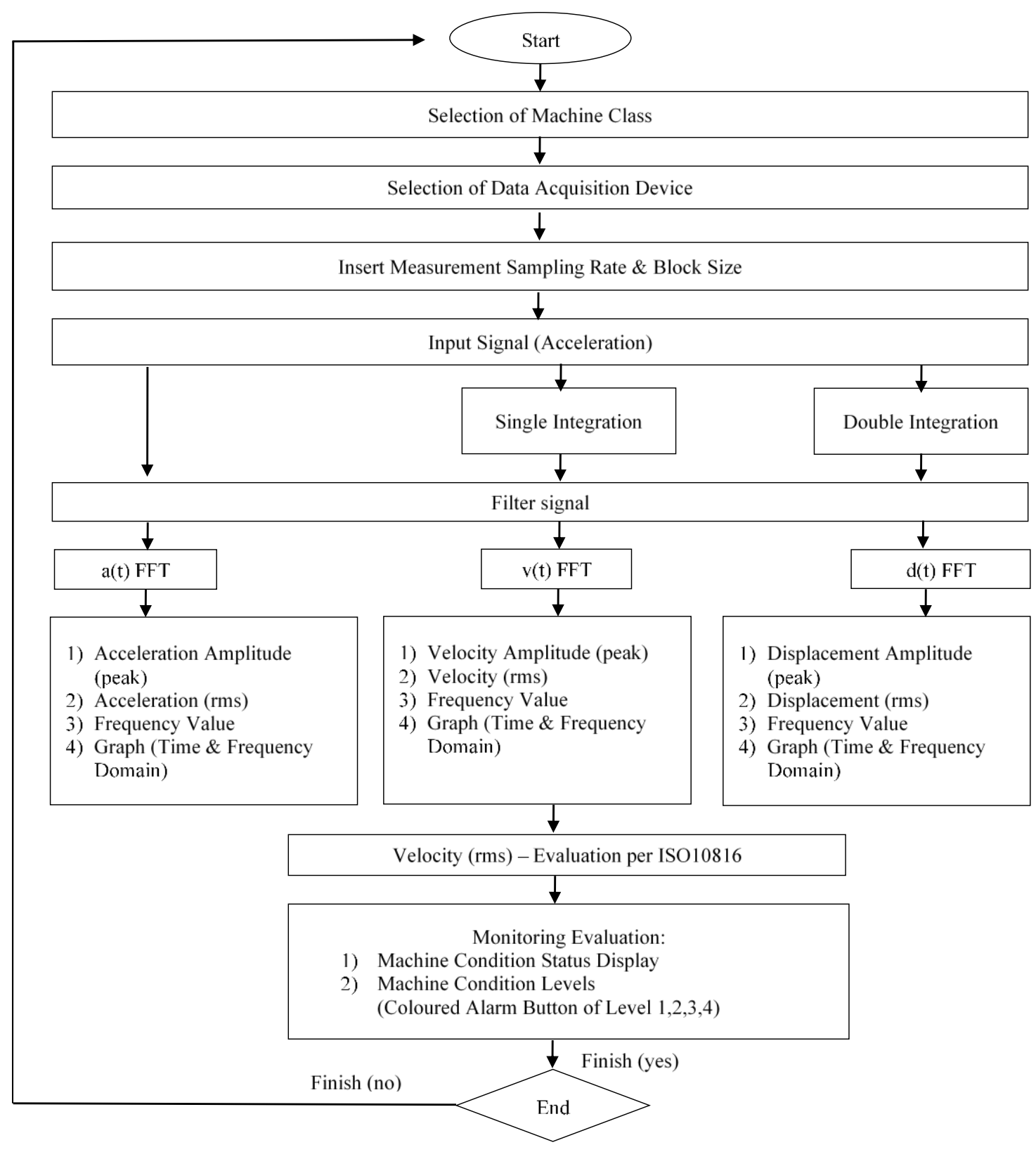

Figure 4. Algorithm of signal processing and visualization for assessment of the machine 


\section{EXPERIMENTAL METHODOLOGY}

\section{Measurement Calibration}

Data acquisition known as a process of gathering and storing data from targeted physical properties in order to gain relevant information. The developed VI has undergone validation process with other software; data acquisition system laboratory (DASYLAB). The additional equipment used for this validation process are listed below and its layout is shown in Figure 5 and 6. The purpose of this validation is to ensure the developed VI gives the correct measurement.

1) Electrodynamic shaker Shaker with sine and noise function - Shaker GW-V4/PA30E.

2) NI-9234 4 - Channel, $51.2 \mathrm{kS} / \mathrm{s} / \mathrm{channel,} \pm 5 \mathrm{~V}, \mathrm{C}$ Series Sound and Vibration Input Module.

3) NI-9269 $100 \mathrm{kS} / \mathrm{s} / \mathrm{ch}$ Simultaneous, $\pm 10 \mathrm{~V}$, Isolated, 4-Channel C Series Voltage Output Module.

4) cDAQ-9178 8-Slot, USB Compact DAQ Chassis.

5) Brüel \& Kjær Piezoelectric CCLD accelerometer Type 4507-B, TEDS with the sensitivity of 98 mv/g @ 9.99 $\mathrm{mV} / \mathrm{mm} / \mathrm{s}^{2}$.

6) Software DASYLAB Version 10.0

The vibration is generated from electrodynamic shaker at the frequency of (i) $30 \mathrm{~Hz}$ and (ii) random noise. For $30 \mathrm{~Hz}$ excitation, 4 stages of the vibration severity are obtained but only three conditions will be reported (shown in Figure 7 and 8) while for random noise, only one stage is shown, as shown in Figure 9. The progress during the validation process is fully observed thoroughly.

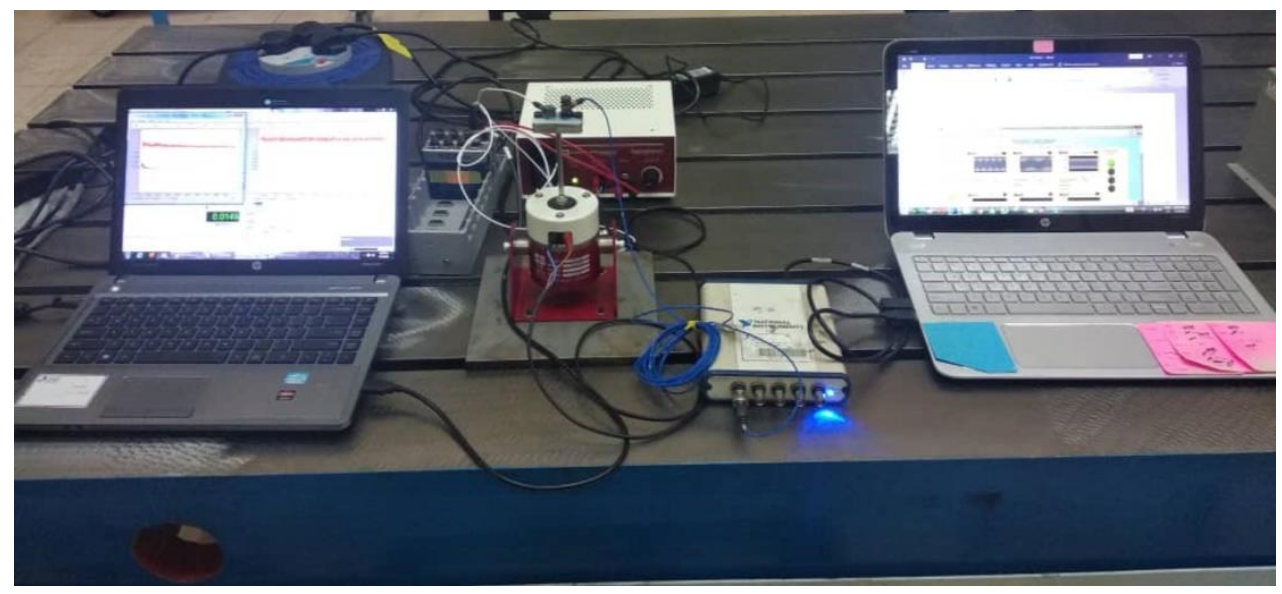

Figure 5. Experimental set up for validation purpose

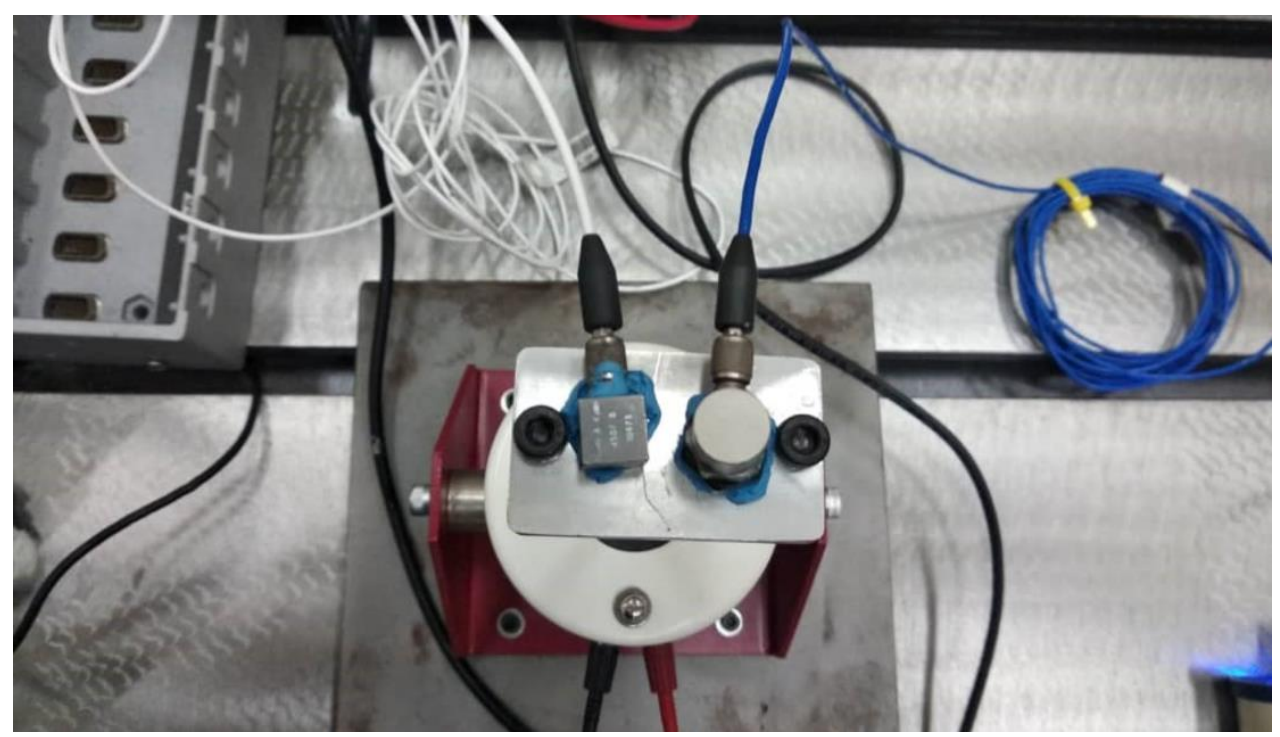

Figure 6. Two accelerometers are mounted on the platform of the shaker

The external excitation comes from the same shaker but the measurement for both VI and DASYLAB using different DAQs and accelerometers. However, the setting for DAQs and accelerometers was set to be similar. As in Figure 7 to 9 , 
the amplitude of acceleration, velocity, and displacement were visualized and denoted by number 1, 2 and 3, respectively. $\mathrm{V}_{\text {rms }}$ resulted from for both VI and DASYLAB shows similarity event though the different is in range of 15 percent. The difference range is considered acceptable as long as both values measured under the same machining condition. At sine wave of $30 \mathrm{~Hz}$, the $\mathrm{V}_{\text {rms }}$ displays in DASYLAB is $0.4204 \mathrm{~mm} / \mathrm{s}$, meanwhile $0.3704 \mathrm{~mm} / \mathrm{s}$ in designed VI. Both condition exhibits vibration severity level 1 which stated as good condition.
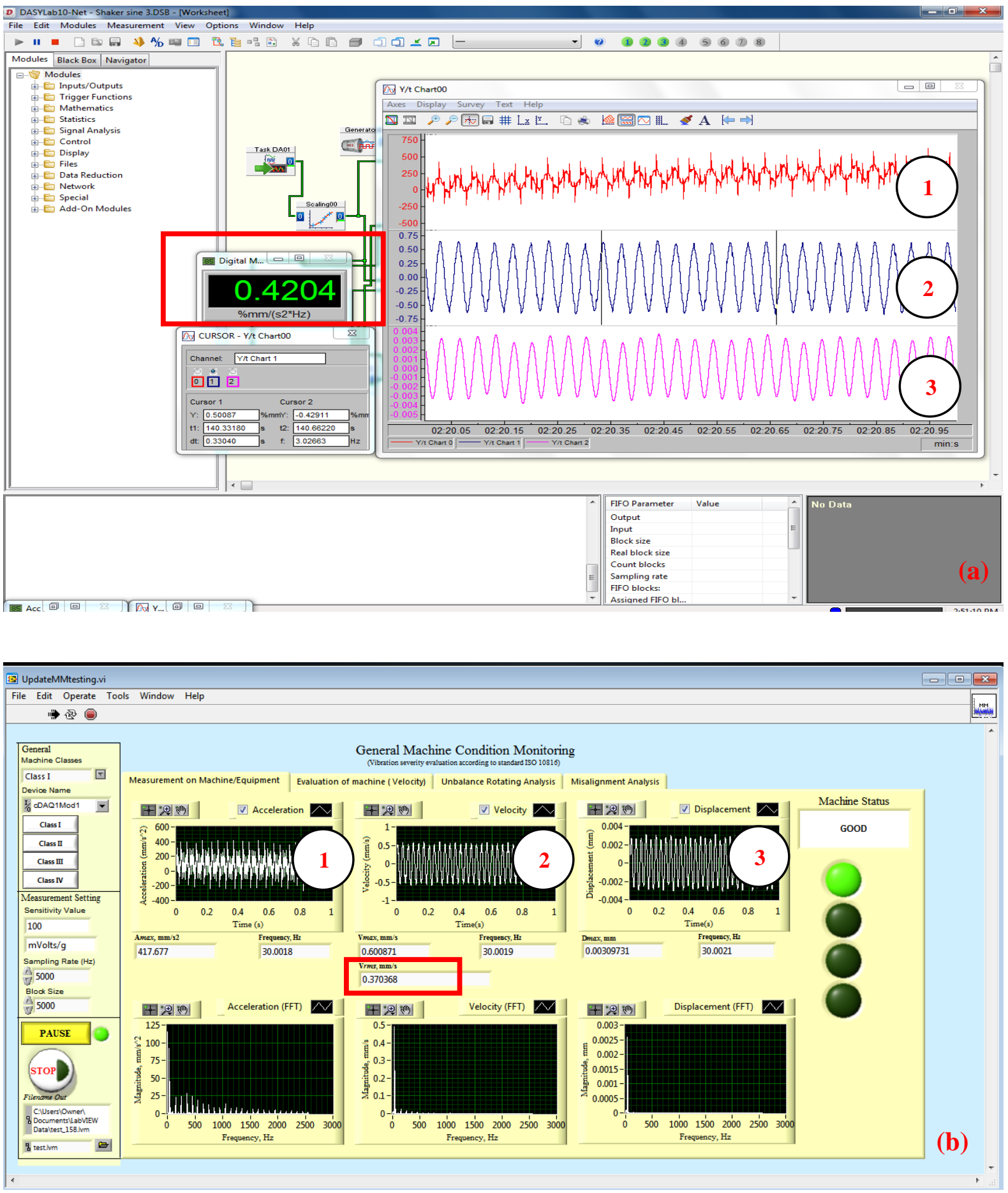

Figure 7. Sine wave at $30 \mathrm{~Hz}$ at vibration severity level 1 (GOOD) in (a) DASYLAB and (b) designed VI

Another result for shaker excitation at sine wave of $30 \mathrm{~Hz}$ was illustrated in Figure 8 . As both of the block size and sampling rate selected were 5000, the frame size of $1 \mathrm{sec}$ were demonstrated. There is a significant increase in vibration measurement value and $\mathrm{V}_{\text {rms. }}$. The maximum acceleration, velocity, and displacement as shown in Figure 8 (b) exhibits at $2848.9200 \mathrm{~mm} / \mathrm{s}^{2}, 14.3290 \mathrm{~mm} / \mathrm{s}$ and $0.0759 \mathrm{~mm}$, individually. $\mathrm{V}_{\mathrm{rms}}$ displays in DASYLAB is $11.2346 \mathrm{~mm} / \mathrm{s}$, meanwhile $10.0713 \mathrm{~mm} / \mathrm{s}$ in designed VI. Both results were different at 11.55 percent comparatively. The condition displays highest vibration severity level which considered as dangerous condition and action is needed immediately. Results plotted during shaker excitation testing shows that the VI system acquire, visualize and analyse the vibration signal in terms of 
acceleration, velocity and displacement successfully on interpretation of machining condition. After shaker testing measurements on different severity level at $30 \mathrm{~Hz}$, the testing will be proceeded at random noise condition.
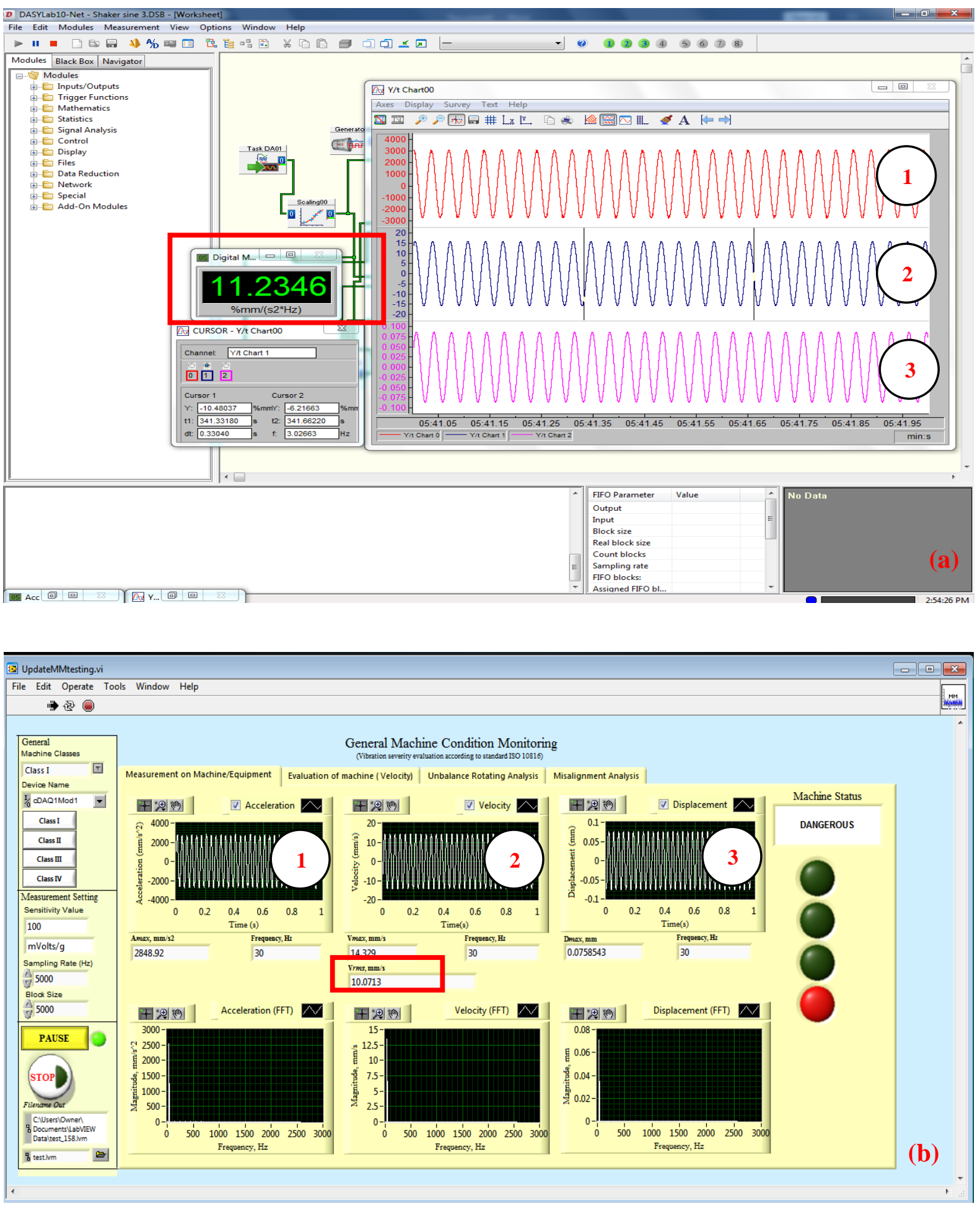

Figure 8. Sine wave at $30 \mathrm{~Hz}$ at vibration severity level 4 (DANGEROUS) in (a) DasyLab and (b) designed VI

Comparative experimental work was done using shaker excitation at random noise and frequency (Figure 9). The frequency excites at approximate 39 to $46 \mathrm{~Hz}$ as illustrated in Figure 9 (b). The $1 \mathrm{sec}$ frame size of data collected shows maximum acceleration, velocity, and displacement as shown in Figure 9 (b) exhibits at $4508.3500 \mathrm{~mm} / \mathrm{s}^{2}, 6.4737 \mathrm{~mm} / \mathrm{s}$ and $0.0162 \mathrm{~mm}$, separately. Moreover, $\mathrm{V}_{\text {rms }}$ displays in DASYLAB is $1.5924 \mathrm{~mm} / \mathrm{s}$, meanwhile $1.7207 \mathrm{~mm} / \mathrm{s}$ in designed VI. Both results were different at 8.06 percent comparatively. The condition demonstrated vibration severity level 2 which measured as acceptable condition. This validation has proved that the developed VI is well-developed. The increment of the voltage input of the shaker increases the acceleration and thus, increases the $V_{\text {rms }}$ as can be seen in Figure 7 to 9 . 

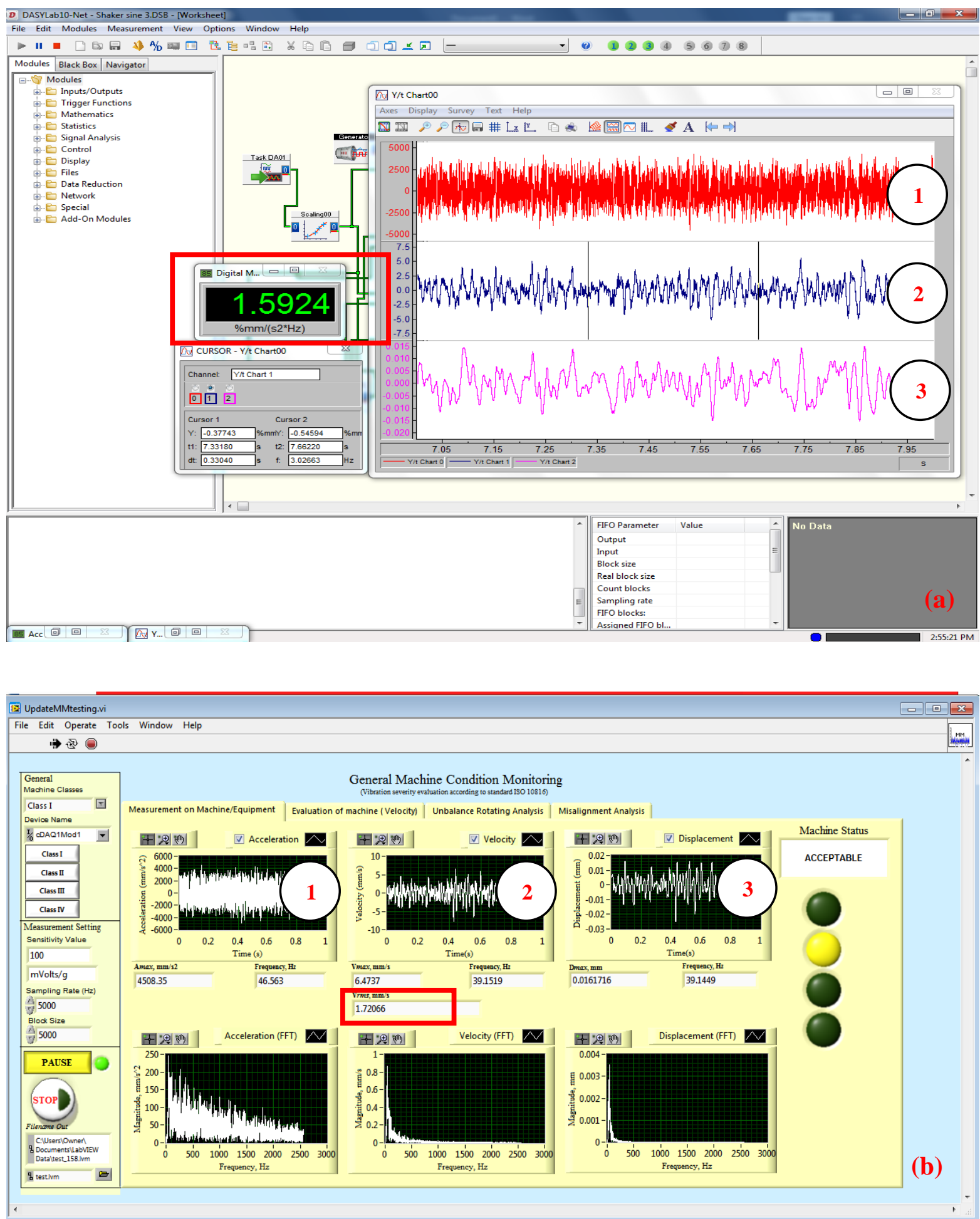

Figure 9. Random noise at vibration severity level 2 (ACCEPTABLE) in (a) DASYLAB and (b) designed VI

\section{Experimental Work}

The workpiece material used was SKD 61 and ductile iron FCD450 for drilling and milling process[20], respectively. The drill bit which made of solid carbide was used with diameter of $8 \mathrm{~mm}$ and length of $210 \mathrm{~mm}$ is selected under rotation speed of $3000 \mathrm{rev} / \mathrm{min}$ with feeds $0.1 \mathrm{~mm} / \mathrm{rev}$. Subsequent, the drilling process for $80 \mathrm{~mm}$, as illustrates in Figure 10, is begun by following straight drilling cutting according to the standard optimum ranges decided for VI module setting. In contrast for milling process, a $16 \mathrm{~mm}$ diameter 4 flutes end mill cutter was used to down mill it with a $25 \%$ radial immersion. A nominal chip thickness of $0.04 \mathrm{~mm}$ per tooth was used to preserved static milling force magnitude and to avoid broad free vibration amplitude due to the disrupted cutting that was applied to the workpiece. Besides, a flexure made of steel was installed during experiment to behave and comply with single dominant mode of vibration. A rotational speed of $3000 \mathrm{rev} / \mathrm{min}$ and axial depths of cut increase from 0.25 to $1.00 \mathrm{~mm}$ were tested to determine if the cutting conditions were stable or not according to the threshold. The accelerometers used in the tests were mounted on the surface 
of a spindle head (drilling) and flexure (milling) at fixed positions (figure 11) to ensure the repeatability of measurement and signal reliability. For the measurement, industrial ICP accelerometer PCB 603C01 was used per values of sensitivity are $101 \mathrm{mV} / \mathrm{g}$. The vibration signals were captured and converted by National Instrument (NI) data acquisition (DAQ) under a sampling rate of 5,000 Hz. The VI is used for the measurement and the evaluation of machine condition according to ISO 10816.

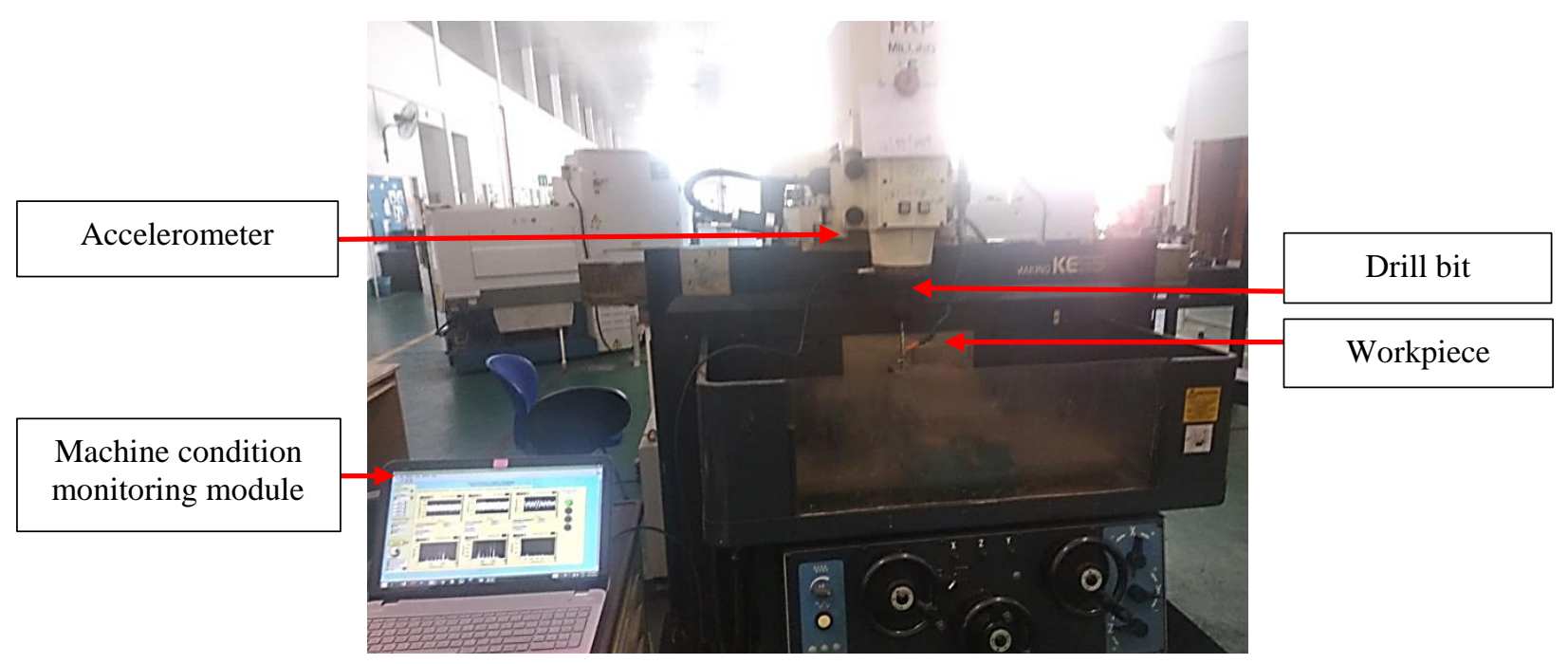

Figure 10. Drilling monitoring process arrangement

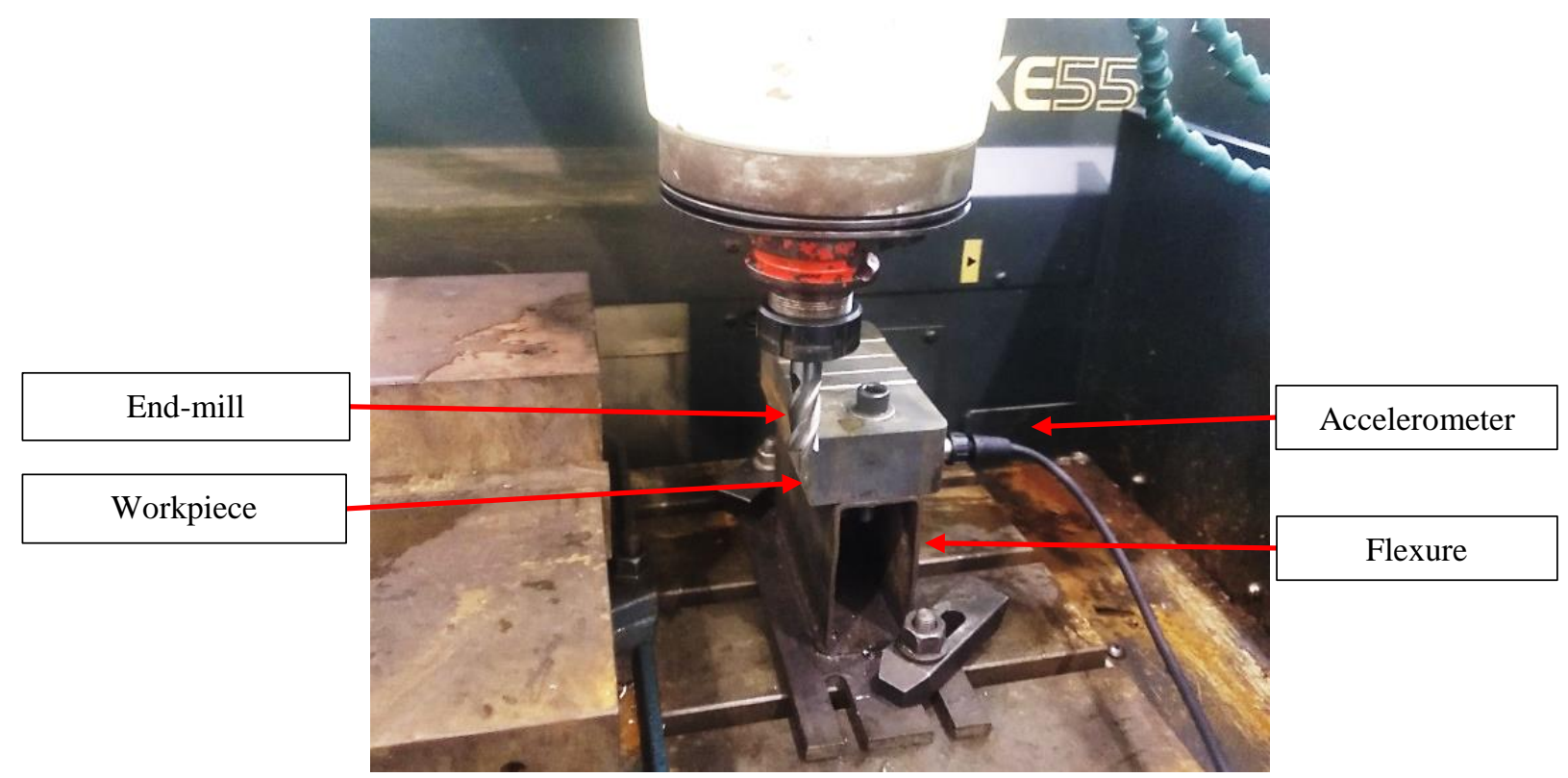

Figure 11. Schematic of chatter milling with flexure

\section{RESULTS AND DISCUSSION}

A number of experiments were conducted for the VI module reliability verification. Four levels are visibly distinguished, if the first condition is good that the system determines the colour green. The next level is acceptable and the colour describing this level is light yellow. The third level is still permissible and colour describing this level is dark Oren. Finally, the last condition is when machine status displays dangerous in red colour alarm button. Prior to monitoring the machine condition in the cutting process, it is vital to confirm the sampling rate, block size, machine classes and device name are correctly selected. Figure 12 displays the VI of monitoring system which is demonstrating acceleration, velocity, and displacement in time and frequency domains for the present condition for drilling and milling process. 

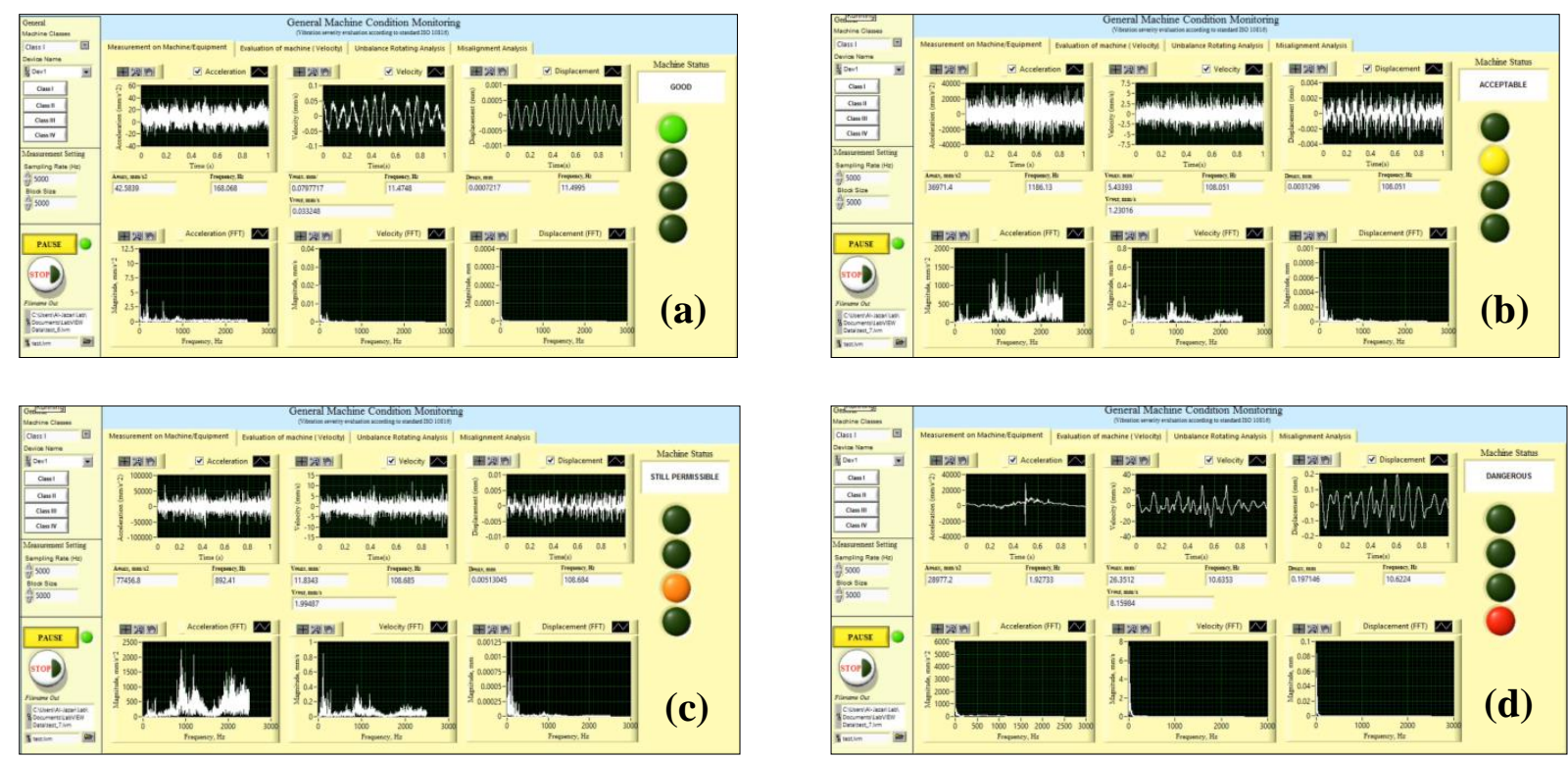

Figure 12. Virtual instrument of machine condition under (a) good, (b) acceptable, (c) still permissible, and (d) dangerous condition

According to the ISO 10816, the cutting process is considered under good condition when the RMS velocity value is lower than $0.720 \mathrm{~mm} / \mathrm{s}$. In Figure 12(a), it shows a small vibration signal which not disturb the machine condition as displayed in velocity. The RMS velocity and peak velocity obtained indicates that current machine condition state is in good condition as $0.03 \mathrm{~mm} / \mathrm{s}$ and $0.08 \mathrm{~mm} / \mathrm{s}$, respectively. Next, the following level of satisfactory RMS velocity is range of 0.721 to $1.800 \mathrm{~mm} / \mathrm{s}$. In Figure 12(b), RMS velocity is $1.23 \mathrm{~mm} / \mathrm{s}$ to classify as acceptable level and so machine condition was in yellow colour. It is an upper level than good condition based on RMS velocity. Both signal for a machine in good and acceptable conditions similar to each other but with higher frequency. For machine class I as small machine, unsatisfactory or alert conditions indicated as it between 1.810 to $4.500 \mathrm{~mm} / \mathrm{s}$ RMS velocity. Figure 12(c) shows RMS velocity value as $1.980 \mathrm{~mm} / \mathrm{s}$ which indicating as still permissible with Oren colour. The highest level of machine condition is unacceptable or danger when RMS velocity reaches higher than $4.510 \mathrm{~mm} / \mathrm{s}$. Figure 12(d) displays RMS velocity of $8.19 \mathrm{~mm} / \mathrm{s}$ to be classified as a dangerous and unacceptable level where machine condition was in red colour. Moreover, this condition requires further action instantly to prevent any damage.

\section{CONCLUSIONS}

A simple and compact vibration based predictive maintenance monitoring module using LabVIEW has been developed and verified in drilling and milling experimental trials presented in this paper. Following conclusions have been obtained from the result and analysis:

1) An online data acquisition module has been developed to acquire, analyze, trigger and illustrate vibration signal simultaneously.

2) The predictive VI built illustrated that it can display machine conditions according to vibration severity chart and ISO 10816 efficiently.

3) The developed VI module correlates the vibration to interpret machining condition.

4) Results obtained from verification experiment showed that the module reliable to measure and illustrate vibration data.

\section{ACKNOWLEDGMENTS}

The authors would like to acknowledge College of Engineering, Universiti Malaysia Pahang (UMP) and Universiti Malaysia Pahang for financial support PRGS 1903180.

\section{REFERENCES}

[1] C. Sanjay, M. Neema, and C. Chin, "Modeling of tool wear in drilling by statistical analysis and artificial neural network," Journal of Materials Processing Technology, vol. 170, no. 3, pp. 494-500, 2005, doi: 10.1016/j.jmatprotec.2005.04.072 
[2] K. Patra, S. K. Pal, and K. Bhattacharyya, "Artificial neural network based prediction of drill flank wear from motor current signals," Applied Soft Computing, vol. 7, no. 3, pp. 929-935, 2007, doi: 10.1016/j.asoc.2006.06.001

[3] R. H. L. da Silva, M. B. da Silva, and A. Hassui, "A probabilistic neural network applied in monitoring tool wear in the end milling operation via acoustic emission and cutting power signals," Machining Science and Technology, vol. 20, no. 3, pp. 386405, 2016, doi: 10.1080/10910344.2016.1191026

[4] S. N. Bhagat and S. Nalbalwar, "LabVIEW based tool condition monitoring and control for CNC lathe based on parameter analysis," in 2016 IEEE international conference on Recent Trends in Electronics, Information \& Communication Technology (RTEICT), 2016: IEEE, pp. 1386-1388, doi: 10.1109/rteict.2016.7808058

[5] G. Shao, D. Kibira, and K. Lyons, "A virtual machining model for sustainability analysis," in International Design Engineering Technical Conferences and Computers and Information in Engineering Conference, 2010, vol. 44113, pp. 875-883, doi: 10.1115/DETC2010-28743.

[6] G. Bucci, F. Ciancetta, E. Fiorucci, A. Fioravanti, A. Prudenzi, and S. Mari, "An IoT condition monitoring system for resilience based on spectral analysis of vibration," in 2020 IEEE International Workshop on Metrology for Industry 4.0 \& IoT, 2020 : IEEE, pp. 38-43, doi: 10.1109/metroind4.0iot48571.2020.9138177

[7] T. Mohanraj, S. Shankar, R. Rajasekar, and M. Uddin, "Design, development, calibration, and testing of indigenously developed strain gauge based dynamometer for cutting force measurement in the milling process," Journal of Mechanical Engineering and Sciences, vol. 14, no. 2, pp. 6594-6609, 2020, doi: 10.1109/metroind4.0iot48571.2020.9138177

[8] A. Chouder, S. Silvestre, B. Taghezouit, and E. Karatepe, "Monitoring, modelling and simulation of PV systems using LabVIEW," Solar Energy, vol. 91, pp. 337-349, 2013, doi: 10.1016/j.solener.2012.09.016

[9] C. Ranga and A. K. Chandel, "Advanced tool based condition monitoring of induction machines by using LabVIEW-A review," in 2015 IEEE UP Section Conference on electrical computer and electronics (UPCON), 2015: IEEE, pp. 1-6, doi: 10.1109/upcon.2015.7456693

[10] S. Shankar, T. Mohanraj, and R. Rajasekar, "Prediction of cutting tool wear during milling process using artificial intelligence techniques," International Journal of Computer Integrated Manufacturing, vol. 32, no. 2, pp. 174-182, 2019, doi: 10.1080/0951192x.2018.1550681

[11] V. Pandiyan, W. Caesarendra, T. Tjahjowidodo, and H. H. Tan, "In-process tool condition monitoring in compliant abrasive belt grinding process using support vector machine and genetic algorithm," Journal of manufacturing processes, vol. 31, pp. 199-213, 2018, doi: 10.1016/j.jmapro.2017.11.014

[12] J. Barreiro, A. Fernández-Abia, A. González-Laguna, and O. Pereira, "TCM system in contour milling of very thick-very large steel plates based on vibration and AE signals," Journal of Materials Processing Technology, vol. 246, pp. 144-157, 2017, doi: 10.1016/j.jmatprotec.2017.03.016

[13] D. Shi, D. Axinte, and N. Gindy, "Development of an online machining process monitoring system: a case study of the broaching process," The International Journal of Advanced Manufacturing Technology, vol. 34, no. 1-2, pp. 34-46, 2007, doi: 10.1007/s00170-006-0588-1

[14] D. Goyal and B. Pabla, "Development of non-contact structural health monitoring system for machine tools," Journal of applied research and technology, vol. 14, no. 4, pp. 245-258, 2016, doi: 10.1016/j.jart.2016.06.003

[15] N. Jamil and A. R. Yusoff, "Effect of Machining Process Parameters on Acceleration Signal in Determining Surface Quality of Milling Process at Ductile Iron," in Proceedings of the International Manufacturing Engineering Conference \& The Asia Pacific Conference on Manufacturing Systems, 2019: Springer, pp. 577-583, doi: 10.1007/978-981-15-0950-6_88

[16] D. G. Zill, Advanced engineering mathematics. Jones \& Bartlett Publishers, 2020.

[17] N. Jamil and A. R. Yusoff, "Electromagnetic actuator for determining frequency response functions of dynamic modal testing on milling tool," Measurement, vol. 82, pp. 355-366, 2016, doi: 10.1016/j.measurement.2016.01.016

[18] H. Kuemmlee, T. Gross, and J. Kolerus, "Machine vibrations and diagnostics the world of ISO," in Industry Applications Society 60th Annual Petroleum and Chemical Industry Conference, 2013: IEEE, pp. 1-13, doi: 10.1109/pcicon.2013.6666052

[19] B. Cahyono, D. Priyanta, and F. R. F. Ramadhan, "Vibration spectrum analysis for indicating damage on turbine and steam generator Amurang Unit 1," International Journal of Marine Engineering Innovation and Research, vol. 2, no. 1, 2017, doi: 10.12962/j25481479.v2i1.2688

[20] N. Jamil and A. Yusoff, "Kurtosis quantification of different minimal quantity lubrication effects in machining cast iron with coated and uncoated tool," in Proceedings of Asia International Conference on Tribology 2018, 2018, vol. 2018: Malaysian Tribology Society, pp. 64-65. 